\title{
IS A POLICY MIX MORE EFFECTIVE THAN INDIVIDUAL POLICIES FOR SME INNOVATION? AN EXPLORATORY ANALYSIS ${ }^{1}$
}

\author{
ANNALISA CALOFFI, MARZIA FREO, STEFANO GHINOI, FEDERICA ROSSI AND MARGHERITA RUSSO \\ DOI: $10.22163 /$ fteval.2019.333
}

\section{INTRODUCTION}

$\mathrm{T}$ The provision of public funds to private firms for the purchase of services, particularly knowledge-intensive ones, has received so far little attention from the evaluation literature (Bakhshi et al., 2015; Bruhn et al., 2018 are notable exceptions). These interventions often target small and medium-sized enterprises (SMEs), providing them with a small amount of public funds that reduce their cost of purchasing services (Storey, 2003). Public funding can take the form of a direct subsidy or a voucher, which firms must use to purchase services from accredited service providers, or sometimes from any provider freely chosen by the beneficiary firm (OECD, 2000; Storey, 2003; IEG, 2013).

These interventions aim to help SMEs to access a variety of knowledge and competencies required for innovation, which are not available within the firm (Vossen, 1998; Storey, 2003). The implicit assumption is that SMEs primarily suffer from constraints on their financial resources, rather than on their capabilities. After receiving the subsidy, SMEs should be able to identify the services they need, as well as the suppliers that can best provide them. However, it is well known that SMEs, may not only lack the financial resources to invest in innovation, but also the capabilities to identify the competences and services they need, or the right suppliers that can provide them (Fontana et al., 2006; OrtegaArgilés et al., 2009). Subsidies for the purchase of knowledge-intensive services address the former problem, but not the latter.

As discussed by Shapira and Youtie (2016), to help SMEs increase their awareness of their needs and how to address them, they could be provided with complementary services, such as technology and innovation advisory services. We argue that such services could be usefully combined with innovation vouchers to increase the performance of SMEs. Technology and innovation advisory services are usually delivered by one or more experts, who carry out a thorough assessment of the firm's current knowledge and technology and an exploration of potential developments. This allows the people involved to undertake a highly customized process of mutual learning, which increases the firm's knowledge of its own innovation needs. Following the assessment, experts can direct the firm to other external service providers that will be able to deliver the specialized knowledge-intensive services it needs.
In several countries, technology and innovation advisory services are provided by, among others, publicly-funded innovation intermediaries, whose aim is to support innovation in SMEs by providing them with a variety of services. Precisely because the advisory services offered by intermediaries could improve SMEs' choice and use of knowledge-intensive services, we expect this combination of interventions to be more effective than the individual instruments.

This study presents an exploratory empirical analysis focused on two interconnected regional innovation policy interventions implemented in Tuscany (Italy). One was the provision of innovation vouchers that SMEs could use to buy knowledge-intensive services from accredited providers, while the other intervention was the creation of intermediaries that could help SMEs to access such services. Since firms could benefit either by only one of the two interventions, or by both, we use a dataset derived from administrative sources to assess whether the policy mix that includes both interventions was more effective than the voucher alone or even the technology and innovation advisory service alone. We adopt a propensity score matching approach applied to the case of multiple treatments, as proposed by Lechner (2002a, 2002b). In particular, we compare three different treatments: (i) the use of innovation vouchers for the purchase of knowledge-intensive services; (ii) the reliance on an intermediary's technology and innovation advisory service; (iii) the combination of the two treatments, i.e. the use of innovation vouchers for the purchase of knowledge-intensive services with guidance from the intermediary.

While policy mixes have been advocated as a response to complex problems (Flanagan et al., 2011; Cunningham et al., 2016), very little empirical evidence is available about the comparative effectiveness of policy mixes with respect to that of the single policies in the mix (Martin, 2016), and no other studies consider the particular combination of innovation vouchers and advisory services. This exploratory study captures an aspect that lies at the core of the policy mix literature, namely that the mix cannot be considered as the simple sum of the single instruments that are included in it (Magro and Wilson, 2013), but it can facilitate the emergence of synergies and complementarities among them.

This study was conducted in the framework of the research project 'Poli.in_Analisi e modellizzazione dei poli di innovazione in Toscana', co-funded by Tuscany Region and the Department of Economics 'Marco Biagi', University of Modena and Reggio Emilia. The authors wish to thank Albino Caporale, Emanuele Fabbri, Angelita Luciani, Serena Brogi, and the managers of the Innovation poles for their support in data collection. Opinions and conclusions expressed are attributable only to the authors. 


\section{POLICY MIXES IN SME POLICY}

The rationale for supporting the acquisition of knowledge-intensive services builds on the idea that, as innovation processes become more complex and the market environment becomes more turbulent, innovative firms need to mobilize a wide range of knowledge and skills, some of which are not available internally. SMEs, which have relatively scarce internal resources, may need support from external experts during one or more phases of the innovation process, from the realization of feasibility studies, to the marketing of innovative products or services (Vossen, 1998; Muller and Zenker, 2001; Storey, 2003; Toivonen, 2007; Shapira and Youtie, 2016). Innovation vouchers are gaining popularity because they are easier to administer than standard grants (Schade and Grigore, 2009) and help knowledge providers to better understand industry needs (Coletti and Landoni, 2018). Innovation vouchers have been found to promote firms' external relationships (BIGGAR Economics, 2010; Sala et al., 2016) particularly with public research institutions (Cornet et al., 2006), and their engagement in further innovation projects (Good and Tiefenthaler, 2011; Bakhshi et al. 2015), in particular for firms that had previously pursued innovative activities (Sala et al., 2016). As innovation vouchers lead firms to adopt a more structured approach to innovation, reducing the time-to-market (Sala et al., 2016), and to engage in more innovation projects and collaborations (Bakhshi et al. 2015), they can be expected to have a positive effect on firms' performance, both in terms of increased sales due to the introduction of innovative products, and in terms of greater efficiency thanks to improvements in internal processes.

Innovation intermediaries are organizations that support firm-level and collaborative innovation, often relying on public funding (Uotila et al., 2012; Knockaert et al., 2014; Caloffi et al., 2018; Russo et al., 2018). Intermediaries' activities frequently include the provision of expert advice on technology and innovation, particularly to SMEs in order to address their capabilities failures (Bessant and Rush, 2005; Knockaert et al., 2014). In fact, intermediaries, which by their nature are able to bridge different types of knowledge and competencies, are well placed to understand the features of the production and innovation processes that are implemented by the firm, the markets it operates in, and those it could enter. Drawing on their assessment of the firm's knowledge and technology, intermediaries identify the firm's strength and weaknesses, and advise it on the implementation of an appropriate innovation strategy (Shapira and Youtie, 2016).

To the best of our knowledge, the above policy instruments have always been investigated individually. However, they could be usefully implemented together, and, to test whether it makes sense to do so, we assess whether the performance of a firm participating in both policies improves more than if the same firm had participated in only one of the two policies. On average, we expect that the performance of firms that receive technology and innovation advice will be greater than that of firms that choose their external services without any particular help. Literature has shown that firms, especially the smallest ones, not only lack the knowledge and competencies that are needed to innovate, but also to understand what their needs are. If this is true, the intermediary can play an important role in guiding firms towards the best possible use of their vouchers, and therefore towards a greater improvement in performance than what would be achieved without such help.

\section{REGIONAL POLICIES IN SUPPORT OF SME INNOVATION: THE CASE OF TUSCANY}

In Italy, regional policy interventions providing SMEs with incentives for the acquisition of knowledge-intensive services have been implemented since the devolution of enterprise policy to regions (Caloffi and Mariani, 2018). In Tuscany, a new policy was launched in 2008, whereby vouchers were issued to SMEs for the acquisition of one or more services drawn from a specific list (the "regional portfolio of knowledge-intensive services"). Forty-four different types of services were listed, including design or other technical expertise, quality testing and marketing of innovative products. Funding came from the European Union's European Regional Development Fund, and could be granted to firms operating in a wide spectrum of sectors. The voucher covered a percentage of the cost of the service, which varied from $60 \%$ to $80 \%$ depending on the type of service. The same firm could apply for more than one voucher both simultaneously and over time. The average voucher amount was relatively small (in line with international practice: OECD, 2008; Good and Tiefenthaler, 2011; Shapira and Youtie, 2016) and, in any event, the same firm could not get more than 200,000 Euros in three years.

In 2011 Tuscany's regional government launched twelve "innovation poles", which were specialized in specific technologies and/or sectors (Russo et al., 2015). SMEs that were members of an innovation pole received several visits from experts that worked for the innovation pole. These experts tried to understand the features of the firm's production and innovation processes, the markets it operated in, and those that it could target. Drawing on their assessment of the firm's knowledge and technology, intermediaries were able to identify the firm's strength and weaknesses and to identify appropriate innovation strategies that the firm could implement.

The two policies mentioned above could be combined. After having identified a feasible innovation strategy, experts provided SMEs with specific information on the innovation vouchers that they could obtain from the regional government. The experts could also help the firms choose the type of service that suited their needs, and support them in their funding applications.

\section{METHODOLOGY AND DATA}

To discover whether the policy mix improves performance compared to the individual innovation policies, we recur to the multiple treatments setting, where the treated group is always formed by firms that are recipients of a specific innovation policy, and control groups are formed by firms treated with one of the two alternative policies in pairwise comparisons.

To identify the treated and control groups, we rely upon administrative data made available by the policymaker running the programmes. We consider two cohorts of treated groups by fixing the time to treatment respectively in 2011 and 2012, which corresponds to the first two years of activity of the innovation poles. In this period, the call for tender related to the vouchers for the acquisition of external services was also open. We consider only these early cohorts because we want to have a sufficiently long time frame to observe the ex-post results of these policies. 
Time-varying data refer to three different time points. In particular, information on the firms' background characteristics refers to one year before the start of the policy, whereas information on the outcomes of interest refers both to the year in which the policy ended and one year after the end of the policy. As a whole: (a) 166 manufacturing SMEs only received vouchers for the acquisition of knowledge-intensive services; (b) 478 manufacturing SMEs only received technology and innovation advisory services thanks to their membership of an innovation pole; (c) 178 manufacturing SMEs participated in both policy interventions.

Given that the services we observe can be of various kinds and cover different phases of the innovation process, we consider a relatively wide range of outcome variables. In particular, we consider: labour productivity, measured as value added per employee; Total Factor Productivity (TFP); total value of sales (in log transformations); and number of employees. While the first two variables refer to measures of productivity or innovation capabilities, the latter can capture some evidence of firm growth. All the data used to build the outcome variables - except for the number of employees - come from the Aida Bureau van Djik database. Data on the number of employees comes from ASIA - Italian Institute of Statistics.

As the number of observations is relatively low /less than one thousand), we use two matching strategies. The first strategy implies that we retain the whole data without imposing the common support condition. Then, a second strategy is developed, according to which we bootstrap 200 samples of 450 firms (150 firms for each one of the three outcomes) and run the multiple propensity matching over bootstrapped samples, by imposing the common support condition. In both cases treated and control firms have been matched by adopting the Mahalanobis distance computed over the two propensities scores, and the set of outcome variables considered, i.e. firm age, log-transformation of sales, the number of employees, per capita value added and TFP at the pretreatment year. We further impose the exact match by 2-digits NACE classification. Here, we will present results attained by the procedure run over bootstrapped samples by imposing the common support condition.

The variables we use in the matching protocol are presented in the following Table 1, which summarizes their averages in the three groups of treated firms. In particular, the couples treated-control are identified by looking at the lagged values of the outcome variables mentioned above (labour productivity, TFP, total value of sales, number of employees). Besides, we also consider firm age and sector (Nace sectors at 2 digits level), which we take from the database ASIA - Italian Institute of Statistics. All these variables are measured one year before policy participation.
Table 1. Averages of control (and outcome) variables by treatment in the pre-treatment period

\begin{tabular}{|l|rr|l|l|}
\hline & \multicolumn{2}{|l|}{$\begin{array}{l}\text { Voucher } \\
\text { Mean }\end{array}$} & \multicolumn{2}{|l|}{$\begin{array}{l}\text { Advisory } \\
\text { services } \\
\text { Mean }\end{array}$} \\
\hline Firm age & 25.6 & 26.6 & \multicolumn{2}{l|}{ Molicy Mix } \\
In(sales) & 15.35 & 15.16 & 15.4 \\
Employees & 32.2 & 53.4 & 35.1 \\
Per-capita value added & 59.0 & 54.6 & 53.9 \\
TFP & 0.407 & 0.281 & 0.380 \\
\hline N. of firms & 166 & 478 & 178 \\
\hline Relative Frequency & 0.202 & 0.581 & 0.216 \\
\hline
\end{tabular}

The table shows that few significant differences across groups emerge in term of pre-entry characteristics. In particular, firms that were treated with the voucher and those that are treated with the policy mix were very similar before policy participation, while firms that only received innovation and technology advisory services were larger and relatively less innovative than the firms in the other two groups.

\section{RESULTS}

Table 2 displays the sign and significance of the average treatment effect on the treated (ATTs) estimated through the bootstrap procedure by imposing the common support condition. The table shows the signs of the ATTs, of the innovation policies on their respective participants during the post-entry period. Cells in dark grey indicate significance at the $5 \%$ level; cells in light grey indicate significance at the $10 \%$ level. Following Lechner (2002b, p.69), a positive ATT indicates "that the effect of the program shown in the row compared with the program appeared in the column is an on-average higher rate of [performance] for [firms which] participate in the program given in the row". Compared with the matching procedure run over the whole sample without common support (whose results are not presented here)ii, the bootstrapped matching procedure presents consistent results, but it is more conservative in finding significant impacts. Moreover, this procedure is a priori more consistent with theoretical aspects. This allows us to be confident of robustness of estimations based on the bootstrapped multiple matching.

Table 2. Average effects on Treated for participants, in rows, versus participants, in columns, measured as difference in outcomes

\begin{tabular}{|c|c|c|c|c|c|c|c|c|c|}
\hline In(Revenues) & Time period & Voucher & $\begin{array}{l}\text { Advisory } \\
\text { service }\end{array}$ & Mix & Employees & Time period & Voucher & $\begin{array}{l}\text { Advisory } \\
\text { service }\end{array}$ & Mix \\
\hline & +1 & & + & - & & +1 & & + & + \\
\hline \multirow[t]{2}{*}{ Voucher } & +2 & & + & - & Voucher & +2 & & + & + \\
\hline & +1 & - & & - & & +1 & + & & + \\
\hline \multirow[t]{2}{*}{$\begin{array}{l}\text { Advisory } \\
\text { service }\end{array}$} & +2 & + & & - & $\begin{array}{l}\text { Advisory } \\
\text { service }\end{array}$ & +2 & + & & - \\
\hline & +1 & + & + & & & +1 & + & + & \\
\hline Mix & +2 & + & + & & Mix & +2 & + & + & \\
\hline
\end{tabular}




\begin{tabular}{|c|c|c|c|c|c|c|c|c|c|}
\hline $\begin{array}{l}\text { Per capita } \\
\text { value added } \\
\text { (thousands } \\
\text { euro) }\end{array}$ & Time period & Voucher & $\begin{array}{l}\text { Advisory } \\
\text { service }\end{array}$ & Mix & TFP & Time period & Voucher & $\begin{array}{c}\text { Advisory } \\
\text { service }\end{array}$ & Mix \\
\hline & +1 & & + & + & & +1 & & + & + \\
\hline \multirow[t]{2}{*}{ Voucher } & +2 & & + & + & Voucher & +2 & & + & - \\
\hline & +1 & + & & - & & +1 & - & & - \\
\hline \multirow[t]{2}{*}{$\begin{array}{l}\text { Advisory } \\
\text { service }\end{array}$} & +2 & + & & - & $\begin{array}{l}\text { Advisory } \\
\text { service }\end{array}$ & +2 & - & & - \\
\hline & +1 & + & + & & & +1 & + & + & \\
\hline Mix & +2 & + & + & & Mix & +2 & + & + & \\
\hline
\end{tabular}

Concerning the effects on revenues, the policy mix has been found to induce a significant increase, of about 30 to $38 \%$ higher than the ones induced by the single voucher or advisory service treatments. Differential significant effects are detected also when vouchers are compared to technology and innovation advisory services. The policy mix outperforms voucher and advisory service treatments also in term of the number of workers (the sum of employees and self-employed workers). In this case positive differentials of 7 to 9 workers are estimated. Also in this case SMEs treated with vouchers outperform those that only received advisory services.

Results in term of per capita value added, which is a measure of labour productivity, are less conspicuous but still positive and significant. Both firms treated with the mix and the voucher programmes outperform firms treated with the advisory services programme only. Further, the policy mix implies a higher labour productivity than the voucher programme only. Considering the TFP outcome variable, the mean effect of the policy mix compared to the advisory service treatment induces up to 16 percentage points of additional TFP for participants in the mix with respect to recipients of advisory services only, and up to 9 percentage points of additional TFP for participants in mix with respect to voucher recipients only. Vouchers are significantly superior to advisory services in term of TFP by about 15 percentage points.

\section{CONCLUSION}

Our analysis finds some support for the claim that the mix of the two interventions works better than each one taken individually. The policy mix outperforms the technology and innovation advisory service alone, and the voucher alone, on all four outcomes. The technology and innovation advisory service seems to engender specific knowledge within the SME that triggers a number of internal mechanisms, which, in turn, generate a higher level of firm performance. Our results in terms of performance appear to be consistent with the mechanisms discussed earlier, which had already been partly described by Shapira and Youtie (2016).

In terms of comparisons between single instruments, vouchers outperform technology and innovation advisory services on all four outcomes. It must also be noted that the most innovative firms (those that have participated in the policy mix, and their matched samples) particularly benefit from the policy mix, compared with vouchers alone or the technology and innovation advisory service alone. Also in the comparison between the two individual policies, the more innovative firms (those that have participated in the vouchers and their matched sample) benefit from vouchers more than from technology and innovation advisory ser- vices. Instead, the less innovative firms (those that used the technology and innovation advisory services only, and their matched samples) do not have any additional benefits from using vouchers or the policy mix.

The mix of innovation vouchers supported by the provision of technology and innovation advisory services, appears to be a promising innovation policy in regard to the increase of revenues and employment, but also of labour and total factor productivity. This however only holds for firms that were more innovative to begin with.

This is a preliminary study building upon a combination of policy programme administrative data and outcome variables derived from widely used company and statistical databases. A more fine-grained investigation where administrative information is complemented with variables derived from a survey of programme participants in all treatment groups, is currently under way.

\section{REFERENCES}

Bakhshi, H., Edwards, J. S., Roper, S., Scully, J., Shaw, D., Morley, L. and Rathbone, N. (2015). Assessing an experimental approach to industrial policy evaluation: Applying RCT+ to the case of Creative Credits. Research Policy, 44(8), 1462-1472.

Bessant, J. and Rush, H. (1995). Building bridges for innovation: The role of consultants in technology transfer. Research Policy, 24(1), 97-114.

BIGGAR Economics (2010). Evaluation of the first phase of the Scottish funding council innovation voucher scheme, Scottish Funding Council.

Bruhn, M., Karlan, D. and Schoar, A. (2018). The impact of consulting services on small and medium enterprises: Evidence from a randomized trial in Mexico. Journal of Political Economy, 126(2), 635-687.

Caloffi, A., and Mariani, M. (2011). Shaping regional policy responses: the design of innovation poles. Policy Studies 32(4), 413-428.

Caloffi, A., Mariani, M., Rossi, F. and Russo, M. (2018). A comparative evaluation of regional subsidies for collaborative and individual $R \& D$ in small and medium-sized enterprises. Research Policy, 47(8), 1437-1447.

Coletti, M. and Landoni, P. (2018). Collaborations for innovation: a meta-study of relevant typologies, governance and policies. Economics of Innovation and New Technology, 27(5-6), 493-509. 
Cornet, M.B., Roomen, V. and Van der Steeg, M. (2006). Do innovation vouchers help SMEs to cross the bridge towards science? CBP Discussion Paper n. 58: CBP.

Cunningham, P., Edler, J., Flanagan, K. and Larédo, P. (2016). The Innovation Policy Mix. In:

Flanagan, K., Uyarra, E.,and Laranja, M. (2011). Reconceptualising the 'policy mix' for innovation. Research Policy 40(5), 702-713.

Fontana, R., Geuna, A. and Matt, M. (2006). Factors affecting university-industry R\&D projects: The importance of searching, screening and signalling. Research Policy, 35(2), 309-323.

Good, B. and Tiefenthaler, B. (2011). Innovation voucher - small is beautiful. Plattform Forschungs- und Technologieevaluierung, Vienna, December.

IEG (2013). Evaluation of the World Bank Group's targeted support for small and medium enterprises (English). Independent Evaluation Group (IEG) approach paper. Washington DC: World Bank.

Knockaert, M., Spithoven, A. and Clarysse, B. (2014). The impact of technology intermediaries on firm cognitive capacity additionality. Technological Forecasting and Social Change, 81, 376-387.

Lechner, M. (2002a). Some practical issues in the evaluation of heterogeneous labour market programmes by matching methods. Journal of the Royal Statistical Society. Series A: Statistics in Society 165(1), 59-82.

Lechner, M. (2002b). Program heterogeneity and propensity score matching: An application to the evaluation of active labor market policies. Review of Economics and Statistics 84(2), 205-220.

Ortega-Argilés, R., Vivarelli, M. and Voigt, P. (2009). RqD in SMEs: a paradox? Small Business Economics, 33(1): 3-11.

OECD (2000).The Bologna Charter on SME Policies. Proceedings of the Bologna Conference.

OECD (2008). A review of local economic and employment development policy approaches in OECD countries. OECD, Paris.

Magro, E. and Wilson, J. R. (2013). Complex innovation policy systems: Towards an evaluation mix. Research Policy 42(9), 1647-1656.

Martin, B. R. (2016). R\&D policy instruments - a critical review of what we do and don't know. Industry and Innovation 23(2), 157-176.
Muller, E. and Zenker, A. (2001). Business services as actors of knowledge transformation: The role of KIBS in regional and national innovation systems. Research Policy 30(9), 1501-1516.

Russo, M., Caloffi, A., Rossi, F., Fiordelmondo, V., and Ghinoi, S. (2015). Evaluating the performance of innovation intermediaries: insights from the experience of Tuscany's innovation poles. fteval Journal for Research and Technology Policy Evaluation 41, 1-6.

Russo, M., Caloffi, A., Rossi, F. and Righi, R. (2018). Innovation intermediaries and performance-based incentives: a case study of regional innovation poles. Science and Public Policy.

Sala, A., Landoni, P. and Verganti, R. (2016). Small and Medium Enterprises collaborations with knowledge intensive services: An explorative analysis of the impact of innovation vouchers. $R$ \& $D$ Management 46 , 291-302.

Schade, S. and Grigore, C. (2009). Availability and Focus on Innovation Voucher Schemes in European Regions, Survey Report prepared by DG ENTR-Unit D2 "Support for innovation", November.

Shapira, P., and Youtie, J. (2016). Impact of technology and innovation advisory services. In Edler, J., Cunningham, P., and Gök, A. (Eds.). Handbook of innovation policy impact. Edward Elgar Publishing.

Storey, D. J. (2003). Entrepreneurship, small and medium sized enterprises and public policies. In Acs, Z. J., GAudretsch, D. B. (Eds) Handbook of entrepreneurship research. Springer, Boston, MA, 473-511.

Toivonen, M. (2007). Innovation policy in services: The development of knowledge-intensive business services (KIBS) in Finland. Innovation 9(34), 249-261.

Uotila, T., Harmaakorpi, V. and Hermans, R. (2012). Finnish mosaic of regional innovation system - assessment of thematic regional innovation platforms based on related variety. European Planning Studies, 20(10), 1583-1602.

Vossen, R.W. (1998). Research note-Relative strengths and weaknesses of small firms in innovation. International Small Business Journal 16(3), 88-94.

i $\quad$ Firm-specific TFPs are estimated at industry level using the semi-parametric Levinsohn and Petrin (2003) approach and, subsequently, they are scaled with respect to industry mean TFPs and log transformed. Log-transformed TFPs (hereafter, TFPs) provide relative measures on how firm-specific productivities deviate from the industry means. 


\section{AUTHORS}

\section{ANNALISA CALOFFI}

Dipartimento di Scienze per l'Economia e I'Impresa, Università di Firenze

Via delle Pandette, 23, 50127 Firenze (Italy)

E: annalisa.caloffi@unifi.it

\section{MARZIA FREO}

Dipartimento di Scienze Statistiche "Paolo Fortunati"

Via Belle Arti 41, Bologna (Italy)

E: marzia.freo@unibo.it

\section{STEFANO GHINOI}

Department of Economics and Management, University of Helsinki

Latokartanonkaari 5, P.0. Box 27 00014, Helsinki, Finland

E: stefano.ghinoi@helsinki.fi

\section{FEDERICA ROSSI}

Department of Management, Birkbeck, University of London

Malet Street, London WC1E 7HX (UK)

E:f.rossi @bbk.ac.uk

\section{MARGHERITA RUSSO}

Dipartimento di Economia, Università di Modena e Reggio Emilia

Via Berengario 51, Modena (Italy)

E: margherita.russo@unimore.it

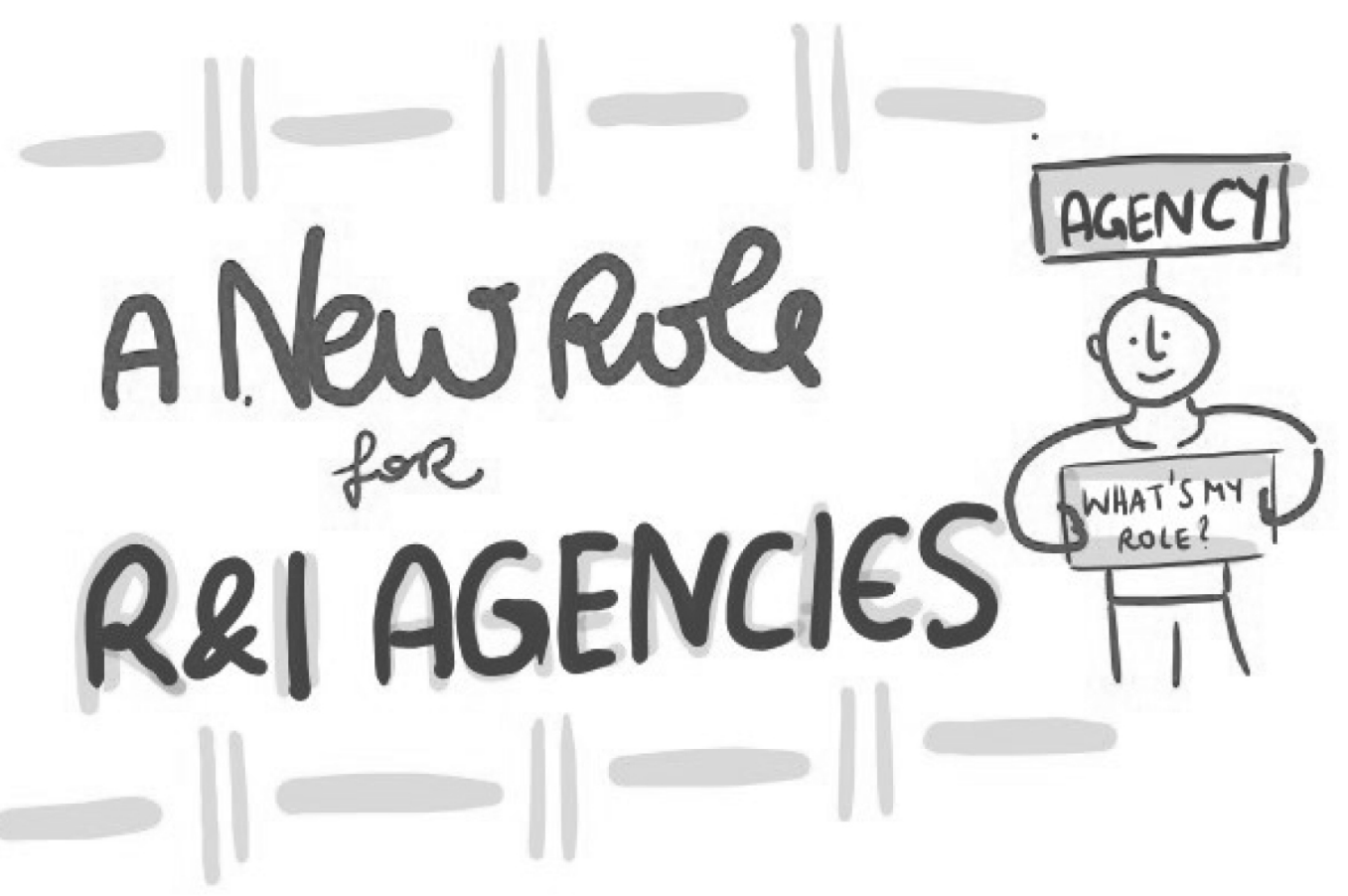

